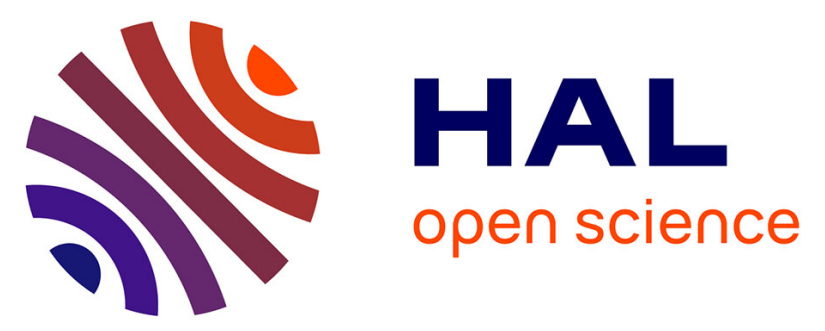

\title{
Development of biomarkers of exposure to xenobiotics in the honey bee Apis mellifera: Application to the systemic insecticide thiamethoxam
}

Alexandra Badiou-Bénéteau, Stephan M. Carvalho, Jean-Luc Brunet, Geraldo A. Carvalho, Audrey Buleté, Barbara Giroud, Luc P. Belzunces

\section{To cite this version:}

Alexandra Badiou-Bénéteau, Stephan M. Carvalho, Jean-Luc Brunet, Geraldo A. Carvalho, Audrey Buleté, et al.. Development of biomarkers of exposure to xenobiotics in the honey bee Apis mellifera: Application to the systemic insecticide thiamethoxam. Ecotoxicology and Environmental Safety, 2012, 82 (1), pp.22-31. 10.1016/j.ecoenv.2012.05.005 . hal-00924275

\section{HAL Id: hal-00924275 \\ https://hal.science/hal-00924275}

Submitted on 26 Sep 2017

HAL is a multi-disciplinary open access archive for the deposit and dissemination of scientific research documents, whether they are published or not. The documents may come from teaching and research institutions in France or abroad, or from public or private research centers.
L'archive ouverte pluridisciplinaire HAL, est destinée au dépôt et à la diffusion de documents scientifiques de niveau recherche, publiés ou non, émanant des établissements d'enseignement et de recherche français ou étrangers, des laboratoires publics ou privés. 


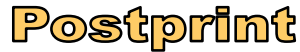

Version définitive du manuscrit publié dans ECOTOXICOLOGY AND ENVIRONMENTAL SAFETY, 2012 vol 82 : 22-31. DOI : http://dx.doi.org/10.1016/..ecoenv.2012.05.005 / Final version of the manuscript published in : ECOTOXICOLOGY AND

ENVIRONMENTAL SAFETY, 2012 vol $82:$ 22-31. DOI : http://dx.doi.org/10.1016/j.ecoenv.2012.05.005

Development of biomarkers of exposure to xenobiotics in the honey bee Apis mellifera: Application to the systemic insecticide Thiamethoxam

\author{
Alexandra BADIOU-BENETEAU ${ }^{1}$, Stephan M. CARVALHO ${ }^{2}$, Jean-Luc BRUNET ${ }^{1}$, \\ Geraldo A. CARVALHO², Audrey BULETÉ ${ }^{3}$, Barbara GIROUD ${ }^{3}$ and Luc P. BELZUNCES ${ }^{1}$
}

${ }^{1}$ INRA, Laboratoire de Toxicologie Environnementale, UMR 406 Abeilles \& Environnement, 84914 Avignon Cedex 9, France.

${ }^{2}$ Universidade Federal de Lavras, Departamento de Entomologia, 37200-000 Lavras/MG, Brazil.

${ }^{3}$ Université de Lyon 1, Institut des Sciences Analytiques, Département Service Central d'Analyse, UMR 5280

CNRS, ENS-Lyon, 5 Rue de la Doua, 69100 Villeurbanne, France

Correspondence should be sent to: Luc P. Belzunces or Alexandra Badiou-Bénéteau

INRA, Laboratoire de Toxicologie Environnementale

UR 406 Abeilles \& Environnement,

84914 Avignon Cedex 9, France.

Tel. +33(0)43272 2604; Fax +33 (0)43272 2602

E-mail: luc.belzunces@avignon.inra.fr and alexandra.badiou@avignon.inra.fr 


\begin{abstract}
This study describes the development of acetylcholinesterase (AChE), carboxylesterases (CaE1, CaE2, CaE3), glutathion-S-transferase (GST), alkaline phosphatase (ALP) and catalase (CAT) as enzyme biomarkers of exposure to xenobiotics such as thiamethoxam in the honey bee Apis mellifera. Extraction efficiency, stability under freezing and biological variability were studied. The extraction procedure achieved good recovery rates in one extraction step and ranged from $65 \%$ (AChE) to $97.3 \%$ (GST). Most of the enzymes were stable at $-20^{\circ} \mathrm{C}$, except ALP that displayed a slight but progressive decrease in its activity. Modifications of enzyme activities were considered after exposure to thiamethoxam at the lethal dose 50\% (LD50, 51.16 ng.bee ${ }^{-1}$ ) and two sublethal doses, LD50/10 (5.12 ng.bee ${ }^{-1}$ ) and LD50/20 (2.56 ng.bee ${ }^{-1}$ ). The biomarker responses revealed that, even at the lowest dose used, exposure to thiamethoxam elicited sublethal effects and modified the activity of CaEs, GST, CAT and ALP. Different patterns of biomarker responses were observed: no response for AChE, an increase for GST and CAT, and differential effects for CaEs isoforms with a decrease in CaE1 and CaE3 and an increase in CaE2. ALP and CaE3 displayed contrasting variations but only at 2.56 ng.bee ${ }^{-1}$. We consider that this profile of biomarker variation could represent a useful fingerprint to characterise exposure to thiamethoxam in the honey bee A. mellifera. This battery of honey bee biomarkers might be a promising option to biomonitor the health of aerial and terrestrial ecosystems and to generate valuable information on the modes of action of pesticides.
\end{abstract}

Keywords Insecticide, Thiamethoxam, Honey bee, Sublethal effect, Biomarker 


\section{Introduction}

Biomarkers reveal information on the environmental health in terms of the anthropogenic factors responsible for individual and population disturbances. Biomarkers can be defined as observable or measurable changes at the molecular, biochemical, cellular, physiological or behavioural levels indicative of the present or past exposure of an organism to xenobiotics (Lagadic et al., 1997). Considerable research on biomarkers has been carried out in marine species (Van der Oost et al., 2003; Bodin et al., 2004). In the terrestrial environment, the honey bee is a particularly pertinent model for the development of biomarkers to assess environmental contamination (Wallwork-Barber et al., 1982; Saifutdinova and Shangaraeva, 1997; Leita et al., 2004). Honey bee can provide a true reflection of environmental quality because, by its intense foraging activity, it is into contact with a large number of pollutants within a radius that generally ranges from 3 to $12 \mathrm{~km}$ around the hive. Few studies have been performed on the development of biomarkers in the honey bee, and most of them have concerned the enzyme acetylcholinesterase (AChE) or hypopharyngeal glands as anatomical biomarkers (Stefanidou et al., 1996; Badiou et al., 2008; Heylen et al., 2011). However, effective assessment of the ecotoxicological impacts of xenobiotics requires an approach that combines several different biomarkers (Roméo et al., 2003) as this will enable a more precise diagnosis of exposure to environmental stressors through a combination of different biological responses.A variety of enzymes are commonly used as biomarkers in numerous species, such as acetylcholinesterase (AChE, EC 3.1.1.7), carboxylesterases (CaEs, EC 3.1.1.1), catalase (CAT, EC 1.11.1.6) and glutathion-S-transferase (GST, 2.5.1.18). However, the honey bee suffers from a lack of pertinent biomarkers to assess its health, especially in the context of bioindication. $\mathrm{AChE}$ is a neural enzyme involved in the precise control of nerve transmission in the cholinergic synapses by hydrolysing the neurotransmitter acetylcholine. The honey bee presents two membrane-bound AChE (93-97\% of total activity) and a soluble form (3-7\% of total activity), mainly localised in the head (Badiou et al., 2007). AChE depression has been widely used as a biomarker of general exposure to pollutants (Stefanidou et al., 1996; Frasco et al., 2005; Tu et al., 2009), but its increase can also be a sign of specific exposure to certain agrochemicals such as deltamethrin (Badiou et al., 2008). CaEs are involved in numerous metabolic processes but can also be considered as phase-I detoxifying enzymes that mainly hydrolyse non-polar carboxyl esters, or as suicide enzymes to inactivate organophosphate or carbamate insecticides (Yu et al., 1984; Dary et al., 1990; Maxwell and Donald, 1992; Gunning et al., 1997; Stone et al., 2002). GST is a phase-II detoxifying enzyme that catalyses the conjugation of reduced glutathion (GSH) to a large number of xenobiotics, resulting in more polar compounds being excreted or further metabolized (Maxwell, 1992). In different honey bee species, GST is mainly localised in the midgut (Diao et al., 2006). GST and CaEs can be induced by numerous different chemicals because of their active role in the 
detoxification of endogenous and exogenous substances (Stone et al., 2002; Barata et al., 2005). However, although recent studies have suggested that GST may also play an important role in protecting tissues from oxidative stress, the primary defence against this stress is assured by catalase (CAT, EC 1.11.1.6) (Hyne and Maher, 2003; Babczynska et al., 2006). CAT is a peroxisomal hydroperoxidase that catalyses the conversion of hydrogen peroxide into oxygen and water, providing an efficient defence system against the toxicity of reactive oxygen species (ROS). Alkaline phosphatase (ALP, EC 3.1.3.1), a digestive enzyme involved in adsorption and transport mechanisms through the hydrolysis of phosphate groups (Moss, 1992), is a valuable diagnostic tool used to monitor certain human diseases. ALP is also involved in the transport of glucose and fatty acids through the membrane of the midgut epithelium, as shown in Bombyx Mori (Vlahovic et al., 2009). In insects, few studies have been performed on the use of ALP as a biomarker. However, Bounias et al. (1996) observed an increase in phosphatase activity after copper treatment in the honey bee which showed that this enzyme could be used as a biomarker in this species. Thus AChE, CaEs, GST, CAT and ALP are involved in processes critical to the survival, performance and defences of the honey bee, at both the neural and metabolic levels, and consequently represent very good candidates to be modulated following exposure to pollutants.

Among potential environmental stressors of honey bees, thiamethoxam is a systemic insecticide of the neonicotinoid family that is widely used against sucking and chewing pests in agriculture. Its physicochemical properties mean that it is applied in a variety of ways, including spraying and seed dressing. Thiamethoxam residues have been measured in pollen as high as 53 $\mathrm{gg} / \mathrm{kg}$ (Mullin et al., 2010). It is therefore highly probable that thiamethoxam is in contact with non-target insects such as honey bees at different levels of exposure. This insecticide acts agonistically on nicotinic acetylcholine receptors (nAChR), without competitive interaction with other neonicotinoids (Tomizawa and Casida, 2003; Tan et al., 2007). In the honey bee brain and ganglions, the nAChR are widely distributed and are involved in pathways that control a variety of physiological functions (Scheidler et al., 1990; Thany and Gauthier, 2005). However, secondary targets may also be affected by xenobiotics, as has already been observed with other pesticides (Loucif-Ayad et al., 2008), and may constitute potential biomarkers. As well as its highly lethal toxicity, thiamethoxam can elicit adverse sublethal effects at low doses and impair learning and memory functions (El Hassani et al., 2008; Aliouane et al., 2009). Such adverse sublethal effects are not limited and different types can be observed in arthropods, and especially the honey bee, following sublethal exposures to pesticides (Desneux et al., 2007). Xenobiotics may impact metabolism, cell signalling, cognitive functions or the integrity of development, but they always have final behavioural and/or physiological effects that can be revealed at individual, organ, tissue, cell or molecular levels. 
At these biological levels, different types of biomarkers can be developed in the honey bee, such as cytochrome oxidase, acetylcholinesterase or $\mathrm{Na}^{+} / \mathrm{K}^{+}$-ATPase (Bendahou et al., 1999; Armengaud et al., 2000; Badiou et al., 2008). However, few data are available on the effects of thiamethoxam at sublethal level on enzyme activities in insect species, and particularly in the honey bee.

The purpose of this study was therefore to develop a set of enzyme biomarkers that could be used to assess the health of the honey bee Apis mellifera. As a first step, we have developed seven biomarkers: acetylcholinesterase (AChE, EC 3.1.1.7), glutathion-S-transferase (GST, EC 2.5.1.18), catalase (CAT, EC 1.11.1.6), alkaline phosphatase (ALP, EC 3.1.3.1) and carboxylesterases (CaE, EC 3.1.1.1), and then we have validated them following the exposure of honey bees to thiamethoxam. This battery of biomarkers may be a valuable tool to detect physiological perturbations induced by stressors and to study the modes of action of stressors. Biomarkers involved in key biological systems not only represent a witness of the bee health but also they can be used with symptomatology and chemical analysis to establish a diagnosis of intoxication by pesticides.

\section{Materials and Methods}

\subsection{Materials}

Antipain, aprotinin, leupeptin, pepstatin A, soybean trypsin inhibitor, monobasic and dibasic sodium phosphate, sodium chloride $(\mathrm{NaCl})$, Triton ${ }^{\circledR} \mathrm{X}-100$, acetylthiocholine iodide (AcSCh.I), 5,5'-dithio-bis(2,nitrobenzoic acid) (DTNB), sodium bicarbonate, $\alpha$ and $\beta$ naphthyl acetate ( $\alpha$-NA or $\beta$-NA), $p$-nytrophenyl acetate ( $p$-NPA), 1,5bis(4-allyldimethylammonium-phenyl)pentan-3-one-dibromide (BW284C51), Fast Garnet GBC; sodium dodecyl sulfate (SDS), hydrogen peroxide $\left(\mathrm{H}_{2} \mathrm{O}_{2}\right)$, monobasic potassium phosphate; ethylenediaminetetraacetic acid (EDTA), 1-chloro-2,4-dinitrobenzene (CDNB), reduced L-glutathion (GSH), acetonitrile, acetone, trishydroxymethylaminomethane (Tris), hydrochloride acid ( $\mathrm{HCl})$, magnesium chloride $\left(\mathrm{MgCl}_{2}\right)$, p-nitrophenyl phosphate (p-NPP) and bovine serum albumin (BSA) were all obtained from Sigma-Aldrich (St Louis, MO, USA). Thiamethoxam (98\% pure) was purchased from Cluzeau Info-Labo (Sainte Foy la Grande, France). Apis mellifera honey bees were grown at the experimental apiary of INRA UMR 406 Abeilles \& Environnement at Avignon, France. The presence of a queen was checked in each colony and the health status of the bees was continuously and carefully monitored.

\subsection{Chemical analysis of thiamethoxam}


Analyses of thiamethoxam were achieved according to the published multi-residue method (Wiest et al., 2011). The control of thiamethoxam concentrations in solutions used for the exposures of bees was performed by liquid chromatography coupled to a triple quadrupole mass spectrometer (LC-ESI-MS/MS). The detection mode was based on Multiple Reaction Monitoring (MRM), which was sensitive and selective. Ionization was achieved by an Electrospray source in positive ion mode. Thiamethoxam was characterized by its retention time, two MRM transitions (quantification MRM (parent ion > fragment ion 1: 292 > 211) and a confirmation MRM (parent ion $>$ fragment ion 2: $292>181)$, and by the ratio of the two transitions $(\mathrm{R}=1.6)$. LC-MS/MS analysis was conducted with a Waters ${ }^{\circledR}$ LC-Quattro-Micro chromatograph equipped with a $1.8 \mu \mathrm{m}$ ID C18-Sphinx RP column (50x2.11 $\mathrm{mm}$ ) (Macherey-Nagel) at a flow rate $0.3 \mathrm{ml} / \mathrm{min}$ and at $40^{\circ} \mathrm{C}$. The two mobile phases were respectively composed of MilliQ water containing $0.3 \mathrm{mM}$ ammonium formate and $0.05 \%$ formic acid (phase A) and 100\% methanol $(\mathrm{MeOH})$ (phase B). Elution was performed by successive gradients: 2-32\% MeOH during 5 min, a plateau at 32\% MeOH for $3 \mathrm{~min}$, 32-100\% MeOH during $5 \mathrm{~min}$, and a plateau at 100\% MeOH for 8 min. The insecticide solutions used to expose the bees to thiamethoxam were $51.2 \mathrm{mg} / \mathrm{L}, 5.12 \mathrm{mg} / \mathrm{L}$ and $2.56 \mathrm{mg} / \mathrm{L}$ and were assayed in quadruplicate, after dilution, by comparison with a calibration curve linear between 0 and 750 $\mu \mathrm{g} / \mathrm{L}\left(\mathrm{r}^{2}=0.9967\right)$.

\subsection{Honey bees and acute exposure to thiamethoxam}

Honey bee foragers were gathered during the summer from the upper honeycombs of a single colony equipped with a queen excluder. The acute contact toxicity of thiamethoxam to bees was assessed by determining the dose-mortality relationship according to the EPPO 170 guideline (EPPO, 2001) but with a requirement for control mortality $\leq 5 \%$. The bees were gathered on the day before the experiment, placed in plastic cages $(10.5 \mathrm{x}$ $7.5 \times 11.5 \mathrm{~cm}$ ) in groups of 30 individuals and allowed to rest overnight at $25 \pm 2^{\circ} \mathrm{C}$ and $60 \%$ relative humidity with Candy and water ad lib. On the day of the experiment, bee health and mortality were checked and the few dead bees were replaced. Between 08:00 and 10:00 hours, the honey bees were mildly anaesthetized with $\mathrm{CO}_{2}$ and $1 \mu \mathrm{L}$ of thiamethoxam solution in acetone, containing the appropriate dose, was applied to the dorsal thorax by means of a Hamilton ${ }^{\circledR}$ microsyringe. Great care was taken to avoid stressing the bees, in order to prevent the UV degradation of thiamethoxam and to achieve random treatments of bees. Two controls were included in the study; one group of bees treated with acetone only, and one group with no treatment. Mortality was recorded 24 $\mathrm{h}$ and $48 \mathrm{~h}$ after treatment and corrected by the control mortality. Immediately after determining the $\mathrm{LD}_{50}$ at $48 \mathrm{~h}$, new series of treatments was performed to expose bees to thiamethoxam at $\mathrm{LD}_{50}\left(51.16 \mathrm{ng} \cdot \mathrm{bee}^{-1}\right), \mathrm{LD}_{50} / 10(5.12$ ng.bee ${ }^{-1}$ ), and $\mathrm{LD}_{50} / 20$ (2.56 ng.bee ${ }^{-1}$ ) doses, in order to further assess their effects on bee biomarkers. After 48 
$\mathrm{h}$, the surviving bees were removed and tissues were sampled as described below, and immediately frozen at $80^{\circ} \mathrm{C}$ until biomarker analysis. The thiamethoxam concentrations in the treatment solutions were checked by LCMS/MS chemical analysis as described above. For the $51.2 \mathrm{mg} / \mathrm{L}, 5.12 \mathrm{mg} / \mathrm{L}$ and $2.56 \mathrm{mg} / \mathrm{L}$ thiamethoxam solutions used to expose the bees, the measured values were $51.32 \pm 0.16,4.96 \pm 0.12$ and $2.46 \pm 0.10 \mathrm{mg} / \mathrm{L}$, respectively (means $\pm S D$, $n=4$ ).

\subsection{Enzyme solubilization}

$\mathrm{AChE}$ and CaEs were extracted from the head of honey bees that had previously been numbed at $-5^{\circ} \mathrm{C}$ before their heads were removed by cutting with a scalpel. To prevent any animal suffering, all tissues used for biomarker isolation were removed from previously anaesthetized and decapitated bees. For each tissue extract, the heads were weighed and extraction medium was added to make a $10 \%(w / v)$ extract. The extraction medium consisted of $10 \mathrm{mM} \mathrm{NaCl}, 1 \%(\mathrm{w} / \mathrm{v})$ Triton X-100 and $40 \mathrm{mM}$ sodium phosphate $\mathrm{pH}$ 7.4, and contained $2 \mu \mathrm{g} / \mathrm{ml}$ antipain, leupeptin and pepstatin A, 25 units/ml aprotinin and $0.1 \mathrm{mg} / \mathrm{ml}$ soybean trypsin inhibitor as protease inhibitors (Belzunces et al., 1988a). Tissue homogenization was performed using a high speed homogenizer TissueLyser II (Qiagen $\left.{ }^{\circledR}\right)$ for three periods of 30 seconds, at 30-second intervals, and the extracts were then centrifuged for $20 \mathrm{~min}$ at 13,000 $\mathrm{g}$. The supernatant was recovered for biochemical analyses and used immediately or stored at $-20^{\circ} \mathrm{C}$. All procedures were carried out at $4^{\circ} \mathrm{C}$. ALP, CAT and GST were extracted from the midgut. For each tissue extract, three midguts were obtained by pulling the stings from honey bees and were then weighed. Extraction medium was then added to make a 10\% (w/v) extract; this consisted of $10 \mathrm{mM} \mathrm{NaCl}$, $40 \mathrm{mM}$ sodium phosphate $\mathrm{pH} 7.4$ and the cocktail of protease inhibitors. The midguts were homogenized and processed as described above for the head enzymes. All procedures were carried out at $4^{\circ} \mathrm{C}$. The efficiency of biomarker extraction was assessed by performing three consecutive extractions during which the centrifugation pellets were re-extracted with the appropriate buffer and the resulting three supernatants were assayed independently for enzyme activity.

\subsection{Enzyme assays}

Biochemical analyses were performed using a Varian, Cary 1E dual-beam spectrophotometer. Protein concentrations were estimated using the method developed by Bradford (1976) with bovine serum albumin as the standard. The enzyme biomarkers were analyzed in different biological compartments of the same honey bees. All enzyme assays were performed in triplicate at $25^{\circ} \mathrm{C}$ after incubating the enzymes for 20 min in the 
assay medium in the absence of substrate. AChE activity was measured at $412 \mathrm{~nm}$ according to the method described by Ellman et al. (1961) with modifications from Belzunces et al. (1988). The final concentrations of the reagents in the reaction medium were $0.3 \mathrm{mM}$ AcSCh.I, $1.5 \mathrm{mM}$ DTNB and $100 \mathrm{mM}$ sodium phosphate buffer at $\mathrm{pH}$ 7.0. Three CaE were monitored: types 1, 2 and 3, classified according to their substrate specificity corresponding to the hydrolysis of $\alpha$-naphtyl acetate ( $\alpha$-NA), $\beta$-naphtyl acetate ( $\beta$-NA) and $p$-nitrophenyl acetate (p-NA), respectively (Gomori, 1953). The crude extract was incubated in a medium containing $1.10^{-4} \mathrm{M}$ BW284C51 as an AChE inhibitor and $100 \mathrm{mM}$ sodium phosphate $\mathrm{pH} 7.4$ for 20 min at $25^{\circ} \mathrm{C}$ in the dark. After incubation, the appropriate substrate ( $\alpha$-NA, $\beta$-NA or p-NA) was added to obtain a final concentration of 0.4 $\mathrm{mM}$. For CaE1 and CaE2, the enzyme reaction was performed for 3 min and stopped with $1.5 \%$ SDS and 0.4 mg.mL ${ }^{-1}$ Fast Garnet GBC. The reaction products were measured at $568 \mathrm{~nm}$ for $\alpha-\mathrm{NA}$ (CaE1) and $515 \mathrm{~nm}$ for $\beta$ NA (CaE2). For CaE3, the reaction was monitored continuously at $410 \mathrm{~nm}$. ALP was monitored continuously at $410 \mathrm{~nm}$ in a medium containing $20 \mu \mathrm{M} \mathrm{MgCl}_{2}, 2 \mathrm{mM}$ p-nitrophenyl phosphate as the substrate and $100 \mathrm{mM}$ Tris-HCl buffer at pH 8.5 (Bounias et al., 1996). GST was measured at $340 \mathrm{~nm}$ in a medium containing $1 \mathrm{mM}$ EDTA, $2.5 \mathrm{mM}$ GSH (reduced glutathion), $1 \mathrm{mM}$ 1-chloro-2,4-dinitrobenzene as the substrate and $100 \mathrm{mM}$ sodium phosphate at $\mathrm{pH}$ 7.4. CAT was measured according to the procedure described by Beers and Sizer (1952) in a medium containing $10 \mathrm{mM} \mathrm{H} \mathrm{H}_{2} \mathrm{O}_{2}$ and $100 \mathrm{mM}$ phosphate at $\mathrm{pH}$ 7.0. The reaction was monitored by the decrease in absorbance at $240 \mathrm{~nm}$ due to the consumption of $\mathrm{H}_{2} \mathrm{O}_{2}$.

For AChE, CaE1-3, CAT and ALP, one unit of enzyme activity was defined as the quantity of enzyme that, under the assay conditions, hydrolysed $1 \mu \mathrm{mol}$ of substrate per min. For GST, one unit of activity corresponded to the quantity of enzyme conjugating $1 \mu \mathrm{mol}$ of GSH per min. Results were expressed in terms of specific and tissue activities corresponding to the activity defined above and then related to the quantity of proteins or tissue, respectively.

\subsection{Stability under freezing}

Healthy honey bees were used to analyse fresh and frozen extracts. Fresh extracts corresponded to the initial control activity. Extracts frozen at $-20^{\circ} \mathrm{C}$ were monitored for 60 days by sampling at different time points after freezing: 3, 7, 14, 21, 30, 45 and 60 days.

\subsection{Statistical analysis}


Statistical analyses were performed using the “DRC” package and R software (Ritz and Streibig 2005). The data corresponded to the mean values \pm standard deviations (SD) of three independent experiments determined in triplicate. For enzyme assays, activity data were analysed using one-way analysis of variance (ANOVA). A difference was considered to be statistically significant when $\mathrm{p} \leq 0.05$.

\section{Results}

\subsection{Enzyme extraction}

The efficiency of biomarker extraction was assessed by analysing the supernatants from three subsequent extractions. The largest proportion of each enzyme was extracted in one extraction step (Fig. 1, Table 1). CaE1, CaE2 and CaE3 displayed a high proportion of enzyme being extracted after the first extraction, with $82.80 \pm$ $0.67 \%, 83.50 \pm 1.07 \%$ and $76.60 \pm 1.43 \%$ of total activity, respectively. AChE showed the lowest proportion of enzyme extracted after the first extraction, with $65.10 \pm 0.82 \%$ of total activity. After the second extraction, CaE1, CaE2 and CaE3 displayed activity of $14.75 \pm 0.48 \%, 16.00 \pm 0.99 \%, 17.90 \pm 0.96 \%$, respectively and AChE showed activity of $25.10 \pm 0.94 \%$. A third extraction was necessary to completely solubilize the membrane enzymes AChE, $\mathrm{CaE} 1, \mathrm{CaE} 2$ and $\mathrm{CaE} 3$, whereas only two extractions were required to extract the soluble enzymes present in the bee midgut. Thus for CAT, GST and ALP, $80.20 \pm 2.81 \%, 97.30 \pm 3.38 \%$ and $88.40 \pm 1.96 \%$ of enzyme, respectively, could be extracted after a single extraction.

\subsection{Stability under freezing}

The analysis of stability under freezing was performed to verify whether the solubilized enzymes could be frozen and assayed at a later stage without any significant loss of activity. In general, the enzymes assayed after 60 days at $-20^{\circ} \mathrm{C}$ exhibited activities that did not differ significantly from those of fresh extracts (Fig. 2 and 3). AChE,

CaE1, CaE2, CaE3, CAT and GST remained stable for 60 days. ALP activity displayed a slight, but progressive, decrease over the 60 -day period to reach $86.5 \%$ of its initial activity. ALP could be considered as stable during the first 20 days of freezing.

\subsection{Effect of thiamethoxam on biomarker activities}

In this study, honey bees were exposed by contact exposure, which corresponded to an exposure during a foliar treatment or to a residual contact exposure with treated plant surfaces. The lethal dose $50 \%\left(L_{50}\right)$ of thiamethoxam was first assessed in order to determine the doses at which the honey bees would be exposed for 
biomarker analysis. The $\mathrm{LD}_{50}$ of thiamethoxam at $48 \mathrm{~h}$ in foragers was $51.16 \mathrm{ng} \cdot \mathrm{bee}^{-1}\left(\mathrm{DF}=18 ; \chi^{2}=24.48 ; \mathrm{CI}_{95}=\right.$ 47.07- 56.28 ng.bee ${ }^{-1}$ ) (data not shown). For biomarker analysis, three doses were studied: 51.16 ng.bee ${ }^{-1}\left(\mathrm{LD}_{50}\right)$ and two sublethal doses of 5.12 ng.bee ${ }^{-1}\left(\mathrm{LD}_{50} / 10\right)$ and 2.56 ng.bee ${ }^{-1}\left(\mathrm{LD}_{50} / 20\right)$. Compared to the controls, the tissue activities of AChE and ALP did not vary with the thiamethoxam doses (Fig. 4A, E). After exposure, CaE1 and CaE2 displayed significant variations in tissue activities whatever the dose (Fig. 4B). A decrease for CaE1 and a significant increase for CaE2 could be seen when compared to the corresponding controls. For these biomarkers, the lowest dose (2.56 ng.bee ${ }^{-1}$ ), induced the strongest effect and corresponded to $7.95 \pm 0.85$ and $15.86 \pm 1.68 \mu \mathrm{mol} / \mathrm{min} / \mathrm{g}$ of tissue for CaE1 and CaE2, respectively (control values: $10.47 \pm 1.38$ and $11.81 \pm$ $1.81 \mu \mathrm{mol} / \mathrm{min} / \mathrm{g}$ of tissue for CaE1 and CaE2, respectively). The tissue activities of CaE3, CAT and GST only presented variations after exposure to the lowest thiamethoxam dose (Fig. 4B, C and D). The tissue activities of CaE3 and GST decreased significantly to reach $8.31 \pm 1.02$ and $29.87 \pm 3.98 \mu \mathrm{mol} / \mathrm{min} / \mathrm{g}$ of tissue, whereas those of CAT increased to $2.99 \pm 0.43 \mathrm{mmol} / \mathrm{min} / \mathrm{mg}$ of tissue when both were compared to their controls (21.38 $\pm 2.98,34.46 \pm 4.37,2.57 \pm 0.35 \mu \mathrm{mol} / \mathrm{min} / \mathrm{g}$ of tissue, respectively). For AChE, CaEs and CAT, both tissue and specific activities displayed similar patterns of variation (Fig. 5A, B and C). However, for GST and ALP, different patterns were observed between tissue and specific activities, thus showing that other proteins could be modulated by thiamethoxam (Fig. 5D and E).

\section{Discussion}

\subsection{Conditions for biomarker analysis}

The development of a biomarker assay is a complex process that depends on numerous parameters, ranging from choosing the correct matrix in order to maintain sample integrity, to assay standardization and accuracy (Bocquené and Galgani, 2004). When determining biological matrices, it must be taken into account the sites of production, the physiology and the distribution of biomarkers. In line with previous studies, we studied biomarkers at their principal location site in the honey bee (Diao et al., 2006; Badiou et al., 2007; Vlahovic et al., 2009). Biomarker activities were not determined in the whole body of the honey bee. After analysing the head, thorax, abdomen (without the gut), and midgut, two tissues were chosen in order to enhance the sensitivity of the biomarkers studied, the head and the midgut. Extraction and storage conditions also need to be optimized and standardized in order to preserve sample integrity and stability. During this study, most of the activity of each enzyme was solubilized in one extraction. The extraction efficiency was around $80 \%$ of total activity for most of the enzymes, although better extraction rates were achieved for the soluble enzymes CAT, GST and ALP. After 
the first extraction, GST displayed the highest extraction rate with $97.30 \pm 3.38 \%$ of total activity, whereas AChE displayed the lowest rate with $65.10 \pm 0.82 \%$ of total activity. The small variation in extraction rates showed that the enzyme recovery rates of the initial extractions were quantitative and representative of the total activity of each enzyme. Thus only one extraction step needs to be carried out to study honey bee biomarkers.

The stability of biomarker activity can be affected by long-term storage. Analyses of stability under freezing revealed that the solubilized enzymes could be frozen and subsequently assayed without a significant loss of activity. Despite the differing stability profiles, the results showed a general stability of the enzymes during freezing at $-20^{\circ} \mathrm{C}$, with a few exceptions. AChE, CaEs, CAT and GST were stable for 60 days and could be measured throughout this period. ALP displayed a slight and progressive decline but could be considered as stable for 20 days, implying that this period should be respected if it were to be used as a biomarker. No loss of activity was observed when intact tissues were stored at $-20^{\circ} \mathrm{C}$ or below for at least 2 years (data not shown).

\subsection{Variability of biomarker responses}

In order to assess the health of the environment, any modulation of biomarkers must be attributable to the effects of pollutants and not to physiological, genetic or seasonal variations. Most enzymes may vary as a function of developmental stage or environmental conditions ( Sridhara and Bhat, 1963; Belzunces et al., 1992; Polyzou et al., 1997; Jovanovic-Galovic et al., 2004). Thompson (1999) described some factors that affect the variability of esterases, such as species, inter-individual and diurnal/seasonal changes, age and gender. In addition, the effects of pollutants may differ according to the physiological state of individuals and particularly their metabolic activity (Sanchez et al., 2007). In the honey bee, it has been shown that age and the season are important factors that contribute to major variations in individual and colony physiology (Belzunces et al., 1992; Crailsheim, 1996; Meled et al., 1998; Decourtye et al., 2003). Consequently, these parameters of variability need to be characterised as clearly as possible in order to validate the responses of enzymatic biomarkers. Measuring biomarkers in emerging honey bees could reduce the variability due to age (Bendahou et al., 1999) but this is not compatible with the notion of biomarkers which implies an analysis of exposed individuals under specific environmental conditions at a given time. For this reason, we investigated biomarker changes in foragers, which are the primary exposed individuals in the colony. Foragers can easily be gathered, either in the field, at the site of exposure to environmental stressors, at the hive entrance or in the upper part of the hive on honeycombs. Summer foragers were selected to reduce the variability linked to seasonal conditions, age and polyethism, and to increase the pertinence of potential biomarker responses. Our results revealed a small biological variability of 
all biomarkers. This means that making a distinction between natural variability and responses to stressors would not be problematic. In other words, small amplitude variations of biomarkers could be detected. We were thus able to highlight the effects elicited by exposure to thiamethoxam, even at low exposure levels.

\subsection{Biomarkers of exposure to thiamethoxam: a differential response profile}

The molecular action of insecticides in honey bees has been the subject of several studies (Bendahou et al., 1999; Bounias et al., 1996; Desneux et al., 2007) but rarely for the purpose of developing biomarkers of exposure to pollutants (Badiou et al., 2008). The action of insecticides involves the modulation of numerous molecular targets that could be the object of biomarker development. Some crucial processes in the survival, performance and defences of the honey bee appear to have the greatest potential for modulation following exposure to pollutants. We therefore chose to investigate a battery of enzyme biomarkers involved at the neural and metabolic levels, including detoxification. Biomarker responses were investigated under laboratory conditions after acute sublethal contact exposure to thiamethoxam. Many neonicotinoids induce toxicity when used at lethal and sublethal levels (Decourtye and Devillers, 2010). In this family, nitro-substituted neonicotinoids such as thiamethoxam are the most toxic to honey bees (Suchail et al., 2000, 2001; Iwasa et al., 2004; European Commission, 2006). Laboratory bioassays have demonstrated the toxicity of thiamethoxam, and its metabolite clothianidin, to honey bees, with contact $\mathrm{LD}_{50}$ values of 30 and 22 ng.bee ${ }^{-1}$, respectively, comparable to the $\mathrm{LD}_{50}$ of imidacloprid. In the present study, thiamethoxam toxicity after acute exposure indicated a high level of contact toxicity in the honey bee, with a LD50 of 51.2 ng.bee ${ }^{-1}$. This value did not differ significantly from those reported by other authors (Decourtye and Devillers, 2010). Neonicotinoids have often been suspected of constituting a threat to honey bees at doses close to or less than 1 ng.bee ${ }^{-1}$ (Aliouane et al., 2009). Having determined the variability of the basal activities of biomarkers in foragers, it was then possible to study the effect of thiamethoxam after the exposure of bees to two sublethal doses, 2.56 and 5.12 ng.bee $^{-1}$, and to the LD50 dose. In order to accurately detect the responses triggered by thiamethoxam, our attention has been focused on tissue activity, the only parameter that reflects the actual variation of a protein in a tissue. Specific activity only provides information on variations affecting a given enzyme marker compared with variation of other proteins. This means that the specific activity is used particularly during protein purification in order to study the enrichment of an enzyme of interest at each purification step. During this study, biomarker responses always occurred at the lowest dose (2.56 ng.bee ${ }^{-1}$ ), whatever the biomarker and the expression of results (tissue or specific activity). Surprisingly, the LD50 and sublethal dose of 5.12 ng.bee $^{-1}$ elicited similar responses. 
Compared to the lowest dose responses, higher doses (5.12 ng.bee ${ }^{-1}$ and LD50) either induced similar effects (as observed for CaE1 and CaE2) or no effect, as observed for CaE3, CAT and GST. Except for CaE1 and CaE2, biomarker responses were often weaker at high doses than at the low dose, suggesting a regulatory mechanism of biomarkers similar to that observed for AChE in honey bees and spiders (Badiou et al., 2008; Babczynska et al., 2006).

Neonicotinoids can induce toxicity via distinct pathways. They can act agonistically on the nicotinic acetylcholine receptor (Tomizawa et al., 1993) but may also exhibit an antagonist action on nicotinic acetylcholine receptors (nAChR) (Seifert and Stollberg, 2005). However, it has been suggested that the toxicity of neonicotinoids may be connected to the existence of high and low affinity binding sites, which implies a more complex mode of action (Nagata et al., 1998; Suchail et al., 2001; Guez et al., 2001, 2003). The existence of two imidacloprid binding sites has been demonstrated in the Aphid Myzus persicae and (Lind et al., 1998, 1999) and in the planthopper Nilaparvata lugens (Li et al., 2010). In the honey bee, the existence of one binding site for imidacloprid and its metabolites has been reported although toxicity experiments have suggested the presence of at least two receptors (Nauen et al., 2001; Suchail et al., 2001; Guez et al., 2001, 2003). However, there is a great discrepancy between the concentration at which $\left[{ }^{3} \mathrm{H}\right]$-imidaclorid binds to membranes $(0.5 \mathrm{nM})$ and the concentration at which imidacloprid and its olefin and 5-OH-imidacloprid metabolites induce an inward current (3-30 $\mu \mathrm{M})$ in cholinergic neurons. It should be noted that this difference in concentrations (ranging 6000 to 60,000 ) is in accordance with the difference in doses necessary to observe same effects during chronic and acute exposure of bees to imidacloprid and its metabolite (up to 100,000) (Suchail et al., 2001). These differences could be explained by nAChR sensitive and resistant to imidacloprid whose existence has been demonstrated in the honey bee (Dupuis et al., 2010, 2011). Thiamethoxam seems to display a particular mode of action and may not act competitively at the acetylcholine binding site of nAChRs (Tan et al., 2007). The conversion of thiamethoxam into its toxic metabolite clothianidin has been proposed as the cause of its biological effect (Nauen et al., 2003). The inability of low doses to induce detoxifying mechanisms in the honey bee has also been considered as an explanation for the toxicity of xenobiotics at low doses (Suchail et al, 2001; Brunet et al. 2005). Thus, the effects of thiamethoxam may result in part from modulation of the detoxifying system after exposure, especially if we consider that the clothianidin metabolite is as toxic as the parent compound.

To minimize oxidative damage to cellular components after exposure to xenobiotics, organisms have developed antioxidant defences. CAT is considered as the primary defence against oxidative damage, and GST is an early 
marker of induction of the detoxifying system and also appears to contribute to cellular protection against oxidative damage (Barata et al., 2005; Babczynska et al., 2006). In the present study, the increase in GST and CAT activities, reaching up to $119 \%$ and $156 \%$ of control activity, respectively, strongly suggests the induction of oxidative stress by thiamethoxam. As well as GST and CAT, CaE2 is also induced by thiamethoxam. Differential effects of thiamethoxam have been observed for CaEs, with an increase for CaE2 that contrasts with a decrease for $\mathrm{CaE} 1$ and $\mathrm{CaE} 3$. It should be noted that, for $\mathrm{CaE} 1$ and $\mathrm{CaE} 2$, the effects occur whatever the dose. Thus, the opposite effect of CaE1 and CaE2 would have been masked if only overall CaE activity had been measured. Consequently, the differential effect of the same xenobiotic substance on CaEs renders these enzymes very useful to distinguish the complex actions of different substances. Significant improvements in the use of biomarkers could therefore be achieved by assaying CaEs individually, especially when the isoenzymes respond differently (Bocquené et al., 1997). Although ALP has rarely been studied in the context of biomonitoring, a significant increase of about $20 \%$ above the control level is observed at the lowest doses, making ALP an interesting biomarker of thiamethoxam that could help to establish differential intoxication diagnoses.

\section{Conclusion}

Biomarker responses after exposure to thiamethoxam revealed that the lowest dose used ( 2.56 ng.bee ${ }^{-1}$ ) had a sublethal action and modified the activities of CaEs, GST, CAT and ALP. These biomarkers constitute an early warning system for exposure to thiamethoxam and other xenobiotics. The biomarker responses allowed us to establish a differential profile of exposure to thiamethoxam which consisted in no response of AChE, an increase of GST and CAT, and a differential effect on CaEs isoforms, with a decrease in CaE1 and CaE3 at the lowest dose and an increase in CaE2. We therefore assume that a differential profile of biomarker modulation could be used as a fingerprint to characterise the exposure of bees not only to thiamethoxam but also to other xenobiotics. Hence, using a combination of biomarkers, the absence of effect on a given biomarker could be considered to be fully informative. No dose-effect was observed for any of the enzymes considered individually, suggesting that it might not be possible to assess exposure levels using these biomarkers, at least within the range of doses tested. However, use of a biomarker battery offers an opportunity to establish differential modulation profiles that could be characteristic of both the environmental stressor and the level of exposure. Thus, in the case of nonmonotonic dose-effect relations, the link between the intensity of exposure and the effects observed might also be reflected by the differential modulation of biomarkers. Consequently, this battery of biomarkers can be regarded as a promising option to biomonitor the health of terrestrial ecosystems. Furthermore, the biomarkers 
could yield valuable information on the physiological processes impaired by environmental stressors, and on the modes of action of pesticides in the honey bee.

In this study, we have studied only the effects of thiamethoxam. It is important to see whether the modulation profile of these biomarkers is family-specific or substance-specific. It is legitimate to think that the probability to obtain an identical modulation profile with other pesticides is very low. Nevertheless, it is important to conduct studies on other pesticides, especially neonicotinoids, before using modulation profiles obtained with this battery of biomarkers. The next step in validation of these biomarkers is to study the perturbations induced in bees under real-life conditions in situ.

\section{Acknowledgements}

We would like to thank the Coordenação de Aperfeiçoamento de Pessoal de Nível Superior, Capes/Brazil, for its financial support for the doctoral scholarship of the second author, and Jean-Paul Vermandère and Jean Aptel for competent beekeeping. This work was supported in part by INRA and grants from the European Union FEOGA Beekeeping programme (INRA-France Agrimer Agreement 08-09 R). 


\section{References}

Aliouane, Y., El Hassani, A. K., Gary, V., Armengaud, C., Lambin, M., Gauthier, M., 2009. Subchronic exposure of honeybees to sublethal doses of pesticides: effects on behavior. Environ. Toxicol. Chem. 28, 113-122.

Armengaud, C., Lambin, M., Gauthier, M., eds. 2002. Effects of imidacloprid on the neural processes of memory in honeybee. In: Devillers, J., Pham-Délègue, M.H. (eds). Honeybees: estimating the enviromental impact of chemicals. CRC Press, Boca Raton, FL, pp85-100.

Babczynska, A., Wilczek, G., Migula, P., 2006. Effects of dimethoate on spiders from metal pollution gradient. Sci. Total Environ. 370, 352-359.

Badiou, A., Brunet, J.L., Belzunces, L.P., 2007. Existence of two membrane-bound acetylcholinesterases in the honeybee head. Arch. Insect Biochem. Physiol. 66, 122-134.

Badiou, A., Meled, M., Belzunces, L.P., 2008. Honeybee Apis mellifera acetylcholinesterase - a biomarker to detect deltamethrin exposure. Ecotoxicol. Environ. Saf. 69, 246-253.

Barata; C., Lekumberri, I., Vila-Escalé, M., Prat, N., Porte, C., 2005. Trace metal concentration, antioxidant enzyme activities and susceptibility to oxidative stress in the tricoptera larvae Hydropsyche exocellata from the Llobregat river basin (NE Spain). Aquat. Toxicol. 74, 3-19.

Beers, R.F., Sizer, I.W., 1952. A spectrophotometric method for measuring the breakdown of hydrogen peroxide by catalase. J. Biol. Chem. 195, 133-140.

Belzunces, L. P., Toutant, J. P., Bounias, M., 1988. Acetylcholinesterase from Apis mellifera head. Evidence for amphiphilic and hydrophilic forms characterized by Triton X-114 phase separation. Biochem. J. 255, 46370.

Belzunces, L.P., Gauthier, M., Colin, M.E., 1992. Acetylcholinesterase in Apis mellifera head during postembryonic development. Existence of a glycoinositol-anchored membrane form at early pupal stages. Comp. Biochem. Physiol. 103B, 57-63.

Bendahou, N., Bounias, M., Fleche, C., 1999. Toxicity of cypermethrin and fenitrothion on the hemolymph carbohydrates, head acetylcholinesterase, and thoracic muscle $\mathrm{Na}+\mathrm{K}+$-ATPase of emerging honeybees (Apis mellifera mellifera. L). Ecotoxicol. Environ. Saf. 44, 139-46.

Bocquené G. et Galgani F. (2004). Les marqueurs biologiques d'effets polluants: l'acétylcholinestérase. Ed. Ifremer, Méthodes d'analyses en milieu marin, Versailles, 28 p.

Bocquené, G., Roig, A., Fournier, D., 1997. Cholinesterases from the common oyster (Crassostrea gigas). Evidence for the presence of a soluble acetylcholinesterase insensitive to organophosphate and carbamate inhibitors. FEBS Lett. 407, 261-6.

Bodin, N., Burgeot, T., Stanisiere, J.Y., Bocquene, G., Menard, D., Minier, C., Boutet, I., Amat, A., Cherel, Y. , Budzinski, H., 2004. Seasonal variations of a battery of biomarkers and physiological indices for the mussel Mytilus galloprovincialis transplanted into the northwest Mediterranean Sea. Comp. Biochem. Physiol. Part 138C, 411-427.

Bounias, M., Kruk, I., Nectoux, M., Popeskovic, D., 1996. Toxicology of Cupric Salts on Honeybees. V. Gluconate and Sulfate Action on Gut Alkaline and Acid Phosphatases. Ecotoxicol. Environ. Saf. 35, 67-76. 
Bradford, M.M., 1976. A rapid and sensitive method for the quantitation of microgram quantities of protein utilizing the principle of protein-dye binding. Anal. Biochem. 72, 248-254.

Brunet, J. L., Badiou, A., Belzunces, L. P., 2005. In vivo metabolic fate of [14C]-acetamiprid in six biological compartments of the honeybee, Apis mellifera L. Pest. Manag. Sci. 61, 742-748.

Crailsheim, K., 1986. Dependence of protein metabolism on age and season in the honeybee (Apis mellifica carnica Pollm). J. Insect Physiol. 32, 629-634.

Dary, O., Georghiou, G. P., Parsons, E., Pasteur, N., 1990. Microplate adaptation of Gomori's assay for quantitative determination of general esterase activity in single insects. J. Econ. Entomol. 83, 2187-92.

Decourtye, A., Lacassie, E., Pham-Delègue, M.H., 2003. Learning performances of honeybees (Apis mellifera L) are differentially affected by imidacloprid according to the season. Pest. Manag. Sci. 59, 269-278.

Decourtye, A., Devillers, J., 2010. Ecotoxicity of neonicotinoid insecticides to bees. Adv. Exp. Med. Biol. 683, 85-95.

Desneux, N., Decourtye, A., Delpuech, J. M., 2007. The sublethal effects of pesticides on beneficial arthropods. Annu. Rev. Entomol. 52, 81-106.

Diao, Q., Yuan, K., Liang, P., Gao, X., 2006. Tissue distribution and properties of glutathione S-transferases in Apis cerana cerana Fabricius and Apis mellifera ligustica Spinola. J. Apic. Res. 45, 145-152.

Dupuis, J. P., Bazelot, M., Barbara, G. S., Paute, S., Gauthier, M., Raymond-Delpech, V., 2010. Homomeric RDL and heteromeric RDL/LCCH3 GABA receptors in the honeybee antennal lobes: two candidates for inhibitory transmission in olfactory processing. J. Neurophysiol. 103, 458-68.

Dupuis, J. P., Gauthier, M., Raymond-Delpech, V., 2011. Expression patterns of nicotinic subunits alpha 2, alpha 7, alpha 8, and beta 1 affect the kinetics and pharmacology of ACh-induced currents in adult bee olfactory neuropiles. J. Neurophysiol. 106, 1604-1613.

El Hassani, A. K., Dacher, M., Gary, V., Lambin, M., Gauthier, M., Armengaud, C., 2008. Effects of sublethal doses of acetamiprid and thiamethoxam on the behavior of the honeybee (Apis mellifera). Arch. Environ. Contam. Toxicol 54, 653-61.

Ellman, G.L., Courtney, K.D., Andres, V., Feather-Stone, R.M., 1961. A new and rapid colorimetric determination of acetylcholinesterase activity. Biochem. Pharmacol. 7, 88-95.

EPPO/OEPP, 2001. EPPO Standards PP1/170(3) Test methods for evaluating the side-effects of plant protection products on honeybees. Bulletin OEPP/EPPO Bulletin 31, 323-330.

European commission (2006) European commission Thiamethoxam SANCO/10390/2002 - rev. final. Available at http://ec.europa.eu/food/plant/protection/evaluation/newactive/thiamethoxam_en.pdf

Frasco, M.F., Fournier, D., Carvalho, F., Guilhermino, L., 2005. Do metals inhibit acetylcholinesterase (AChE)? Implementation of assay conditions for the use of AChE activity as a biomarker of metal toxicity. Biomarkers. 10, 360-375.

Gomori, G., 1953. Human esterases. J. Lab. Clin. Med. 42, 445-453.

Guez, D., Belzunces, L. P., Maleszka, R., 2003. Effects of imidacloprid metabolites on habituation in honeybees suggest the existence of two subtypes of nicotinic receptors differentially expressed during adult development. Pharmacol. Biochem. Be. 75, 217-222.

Guez, D., Suchail, S., Gauthier, M., Maleszka, R., Belzunces, L. P., 2001. Contrasting effects of imidacloprid on habituation in 7- and 8-day-old honeybees (Apis mellifera). Neurobiol. Learn. Mem. 76, 183-191. 
Gunning, R. V., Moores, G. D., Devonshire, A. L., 1997. Esterases and Fenvalerate Resistance in a Field Population ofHelicoverpa punctigera(Lepidoptera: Noctuidae) in Australia. Pestic. Biochem. Physiol. 58, 155-162.

Heylen, K., Gobin, B., Arckens, L., Huybrechts, R., Billen, J., 2011. The effects of four crop protection products on the morphology and ultrastructure of the hypopharyngeal gland of the European honeybee, Apis mellifera. Apidologie 42, 103-116.

Hyne, R.V., Maher, W.A., 2003. Invertebrate biomarkers: links to toxicosis that predict population decline. Ecotoxicol. Environ. Safety. 54, 366-374.

Iwasa, T., Motoyama, N., Ambrose, J. T., Roe, R. M. R. M., 2004. Mechanism for the differential toxicity of neonicotinoid insecticides in the honey bee, Apis mellifera. Crop Prot. 23, 371-378.

Jovanovic-Galovic, A., Blagojevic, D.P., Grubor-Lajsic, G., Worland, R., Spasic, M.B., 2004. Role of antioxidant defense during different stages of preadult life cycle in European corn borer (Ostrinia nubilalis, Hubn.): Diapause and metamorphosis. Arch. Insect Biochem. Physiol. 55, 79-89.

Lagadic, L., Caquet, T., Amiard, J.C., Ramade, F., 1997. Biomarqueurs en Ecotoxicologie, Aspects Fondamentaux, Masson, Paris, 419 p.

Li, J., Shao, Y., Ding, Z., Bao,H, Liu, Z., Han, Z., Millar, N.S., 2010. Native subunit composition of two insect nicotinic receptor subtypes with differing affinities for the insecticide imidacloprid. Insect Biochem. Mol. Biol. 40, 17-22.

Lind, R.J., Clough, M.S., Reynolds, S.E., Early, F.G.P., 1998. [ $\left.{ }^{3} \mathrm{H}\right]-$ Imidacloprid labels high- and low-affinity nicotinic acetylcholine receptors-like binding sites in the Aphid Myzus persicae (Hemiptera: Aphididae). Pestic. Biochem. Physiol. 62, 3-14.

Lind, R., Clogh, M.S., Earley, F.G.P., Wonacott, S., Reynolds, S.E., 1999. Characterisation of multiple alphabungarotoxin binding sites in the aphid Myzus persicae (Hemiptera: Aphididae). Insect Biochem. Mol. Biol. 29, 979-988.

Leita, L., Muhlbachova, G., Cesco, R., Barbattini, R., Mondini, C., 2004. Investigation of the use of honeybees and honeybee products to assess heavy metals contamination. Environ. Monitor. Assess. 43, 1-9.

Loucif-Ayad, W., Aribi, N., Soltani, N., 2008. Evaluation of secondary effects of some acaricides on Apis mellifera intermissa (Hymenoptera, Apidae): acetylcholinesterase and Glutathion S-transferase activities. European Journal of Scientific Research 21, 642-649.

Maxwell, D.M., 1992. The specificity of carboxylesterase protection against the toxicity of organophosphorus compounds. Toxicol. Appl. Pharmacol. 114, 306-312.

Meled, M., Thrasyvoulou, A., Belzunces, L. P., 1998. Seasonal variations in susceptibility of Apis mellifera to the synergistic action of prochloraz and deltamethrin. Environ. Toxicol. Chem. 17, 2517-2520.

Mullin, C. A., Frazier, M., Frazier, J. L., Ashcraft, S., Simonds, R., Vanengelsdorp, D., Pettis, J. S., 2010. High levels of miticides and agrochemicals in North American apiaries: implications for honey bee health. PLoS ONE 5, e9754.

Nagata, K., Song, J. H., Shono, T., Narahashi, T., 1998. Modulation of the neuronal nicotinic acetylcholine receptor-channel by the nitromethylene heterocycle imidacloprid. J. Pharmacol. Exp. Ther. 285, 731-738.

Nauen, R., Ebbinghaus-Kintscher, U., Salgado, V. L., Kaussmann, M., 2003. Thiamethoxam is a neonicotinoid precursor converted to clothianidin in insects and plants. Pest. Manag. Sci. 76, 55-69. 
Nauen, R., Ebbinghaus-Kintscher, U., Schmuck, R., 2001. Toxicity and nicotinic acetylcholine receptor interaction of imidacloprid and its metabolites in Apis mellifera (Hymenoptera : Apidae). Pest. Manag. Sci. 57, 577-586.

Moss, D.W., 1992. Perspectives in alkaline phosphatase research. Clin. Chem. 38, 2486-2492.

Polyzou, A., Debras, J.F., Belzunces, L.P., 1997. Changes in acetylcholinesterase during pupal development of Apis mellifera queen. Arch. Insect Biochem. Physiol. 36, 69-84.

Ritz, C., Streibig, J.C., 2005. Bioassay Analysis Using R. J. Stat. Softw. 12.

Roméo, M., Mourgaud, Y., Geffard, A., Gnassia-Barelli, M., Amiard, J.C., Budzinski, H., 2003. Multimarker approach in transplanted mussels for evaluating water quality in Charentes, France, coast areas exposed to different anthropogenic conditions. Environ. Toxicol. 18, 295-305.

Saifutdinova, Z., Shangaraeva, G., 1997. Honeybee populations as ecotoxicological indicators. Mutat. Res. Fundam. Mol. Mech. Mugag. 379, 596.

Sanchez, W., Ait-Aissa, S., Palluel, O., Ditche, J. M., Porcher, J. M., 2007. Preliminary investigation of multibiomarker responses in three-spined stickleback (Gasterosteus aculeatus L.) sampled in contaminated streams. Ecotoxicology 16, 279-287.

Seifert, J., Stollberg, J., 2005. Antagonism of a neonicotinoid insecticide imidacloprid at neuromuscular receptors. Environ. Toxicol. Pharmacol. 20, 18-21.

Scheidler, A., Kaulen, P., Bruning, G., Erber, J., 1990. Quantitative autoradiographic localization of [125I]alphabungarotoxin binding sites in the honeybee brain. Brain Res. 534, 332-335.

Sridhara, S., Bhat, J.V., 1963. Alkaline and acid phosphatases of the silkworm, Bombyx mori L. J. Insect Physiol. 9, 693-701.

Stefanidou, M., Koutselinis, A., Pappas, F., Methenitou, G., 1996. Bee head acetylcholinesterase as an indicator of exposure to organophosphate and carbamate insecticides. Vet. Hum. Toxicol. 38, 420-422.

Stone, D., Jepson, P., Laskowski, R., 2002. Trends in detoxification enzymes and heavy metal accumulation in ground beetles (Coleoptera: Carabidae) inhabiting a gradient of pollution. Comp. Biochem. Physiol. 132C, 105-112.

Suchail, S., Guez, D., Belzunces, L. P., 2000. Characteristics of imidacloprid toxicity in two Apis mellifera subspecies. Environ. Toxicol. Chem. 19, 1901-1905.

Suchail, S., Guez, D., Belzunces, L. P., 2001. Discrepancy between acute and chronic toxicity induced by imidacloprid and its metabolites in Apis mellifera. Environ. Toxicol. Chem. 20, 2482-2486.

Tan, J., Galligan, J. J., Hollingworth, R. M., 2007. Agonist actions of neonicotinoids on nicotinic acetylcholine receptors expressed by cockroach neurons. Neurotoxicology 28, 829-842.

Thany, S. H., Gauthier, M., 2005. Nicotine injected into the antennal lobes induces a rapid modulation of sucrose threshold and improves short-term memory in the honeybee Apis mellifera. Brain Res. 1039, 216-219.

Thompson, H.M., 1999. Esterases as markers of exposure to organphosphates and carbamates. Ecotoxicology 8, 369-384.

Tomizawa, M., Casida, J. E., 2003. Selective toxicity of neonicotinoids attributable to specificity of insect and mammalian nicotinic receptors. Annu Rev Entomol 48, 339-364.

Tomizawa, M., Yamamoto, I., 1993. Structure-Activity-Relationships of Nicotinoids and Imidacloprid Analogs. J. Pestic. Sci. 18, 91-98. 
Tu, H.T., Silvestre, F., Scippo, M.L., Thome, J.P., Phuong, N.T., Kestemont, P., 2009. Acetylcholinesterase activity as a biomarker of exposure to antibiotics and pesticides in the black tiger shrimp (Penaeus monodon). Ecotoxicol. Environ. Saf. 72, 1463-1470.

Van Der Oost, R., Beyer, J., Vermeulen, N.P.E., 2003. Fish bioaccumulation and biomarkers in environmental risk assessment: a review. Environ. Toxicol. Pharmacol. 13, 57-149.

Vlahovic, M., Lazarevic, J., Peric-Mataruga, V., Ilijin, L., Mrdakovic, M., 2009. Plastic responses of larval mass and alkaline phosphatase to cadmium in the gypsy moth larvae. Ecotoxicol. Environ. Saf. 72, 1148-1155.

Wallwork-Barber, M.K., Ferenbaugh, R.W., Gladney, E., 1982. The use of honeybees as monitors of environmental pollution. Am. Bee J. 122, 770-772.

Wiest, L., Bulete, A., Giroud, B., Fratta, C., Amic, S., Lambert, O., Pouliquen, H., Arnaudguilhem, C., 2011. Multi-residue analysis of 80 environmental contaminants in honeys, honeybees and pollens by one extraction procedure followed by liquid and gas chromatography coupled with mass spectrometric detection. J. Chromatogr. A. 1218, 5743-5756.

Yu, S. J., Robinson, F. A., Nation, J. L., 1984. Detoxication capacity in the honey bee, Apis mellifera L. Pestic. Biochem. Physiol. 22, 360-368. 
Figure 1. Recovery rates of biomarkers. AChE and CaEs were extracted from heads and CAT, GST and ALP from midguts. After successive extractions, supernatants corresponding to extract 1,2 and 3 were kept and subjected to analysis. Data corresponded to means \pm SD of 15 repetitions performed in triplicate.

Figure 2. Stability to freezing of membrane biomarkers. Head extracts of healthy honey bees were frozen at $-20^{\circ} \mathrm{C}$ after extraction and assayed at different times during a 60-day period. (A) AChE, (B) CaE1; (C) CaE2, (D) CaE3. Control values correspond to the initial activities before freezing. Data corresponded to means \pm SD of 12 repetitions performed in triplicate. Values were not statistically different at $\mathrm{p}=0.05$.

Figure 3. Stability to freezing of soluble biomarkers. Midgut extracts of healthy honey bees were frozen at $-20^{\circ} \mathrm{C}$ and assayed at different times during a 60-day period (n=15). (A) GST, (B) CAT; (C) ALP. Control values correspond to the initial activities before freezing. Data corresponded to means \pm SD of 12 repetitions performed in triplicate. Values between 3 and 60 days were not statistically different at $\mathrm{p}=0.05$.

Figure 4. Effects of thiamethoxam on biomarkers. Biomarker levels were expressed as tissue activities. Bees were subjected to an acute contact exposure to thiamethoxam at the doses of 0 (Controls), 2.56, 5.12 and 51.16 ng.bee $^{-1}$. AChE (A), CaEs (B), CAT (C), GST (D) and ALP (E). Data corresponded to means \pm SD of 9 repetitions performed in triplicate. Asterisks indicate a significant difference with the control: $(*) \mathbf{p} \leq \mathbf{0 . 0 5}: \mathbf{p}=$ 0.031 for CaE1, $p=0.025$ for CAT and $p=0.030$ for GST. $(* *) p \leq 0.01: p=0.006$ for CaE1 at $2.6 \mathrm{ng}^{*}$ bee $^{-1}$, $\mathrm{p}=0.0071$ for CaE1 at 5.2 ng.bee ${ }^{-1}, 0.0075$ for CaE1 at 51.2 ng.bee $^{-1}, p=0.0034$ for CaE2 at 2.6 ng.bee $^{-1}, p$ $=0.0030$ for CaE 2 at 5.2 ng.bee $^{-1}, p=0.0025$ for CaE2 at 51.2 ng.bee $^{-1}$ and $p=0.0063$ for CaE3 at 5.2 ng.bee ${ }^{-1}$.

Figure 5. Effects of thiamethoxam on biomarkers. Biomarker levels were expressed as specific activities. Bees were subjected to an acute contact exposure to thiamethoxam at the doses of 0 (Controls), 2.56, 5.12 and 51.16 ng.bee ${ }^{-1}$. AChE (A), CaEs (B), CAT (C), GST (D) and ALP (E). Data corresponded to means \pm SD of 9 repetitions performed in triplicate. Asterisks indicate a significant difference with the control: $(*) \mathbf{p} \leq \mathbf{0 . 0 5}: \mathbf{p}=$ 0.015 for CaE3, $p=0.025$ for CAT at 5.1 ng.bee $^{-1}$ and $p=0.031$ for GST at 5.1 ng.bee ${ }^{-1}$ ( $(*) p \leq 0.01: p=$ 0.0052 for CaE1 at 2.6 ng.bee ${ }^{-1}, p=0.0061$ for CaE1 at 5.2 ng.bee $^{-1}, 0.0065$ for CaE1 at 51.2 ng.bee ${ }^{-1}, p=$ 0.0033 for CaE2 at 2.6 ng.bee ${ }^{-1}, p=0.0028$ for CaE 2 at 5.2 ng.bee $^{-1}, p=0.0022$ for CaE2 at 51.2 ng.bee ${ }^{-1}, p$ 
$=0.0023$ for CAT at 2.6 ng.bee $^{-1}, p=0.0051$ for GST at 2.6 ng.bee $^{-1}, p=0.0047$ for GST at 5.1 ng.bee $^{-1}$ and $\mathrm{p}=0.0072$ for ALP at 2.6 ng.bee $^{-1}$.

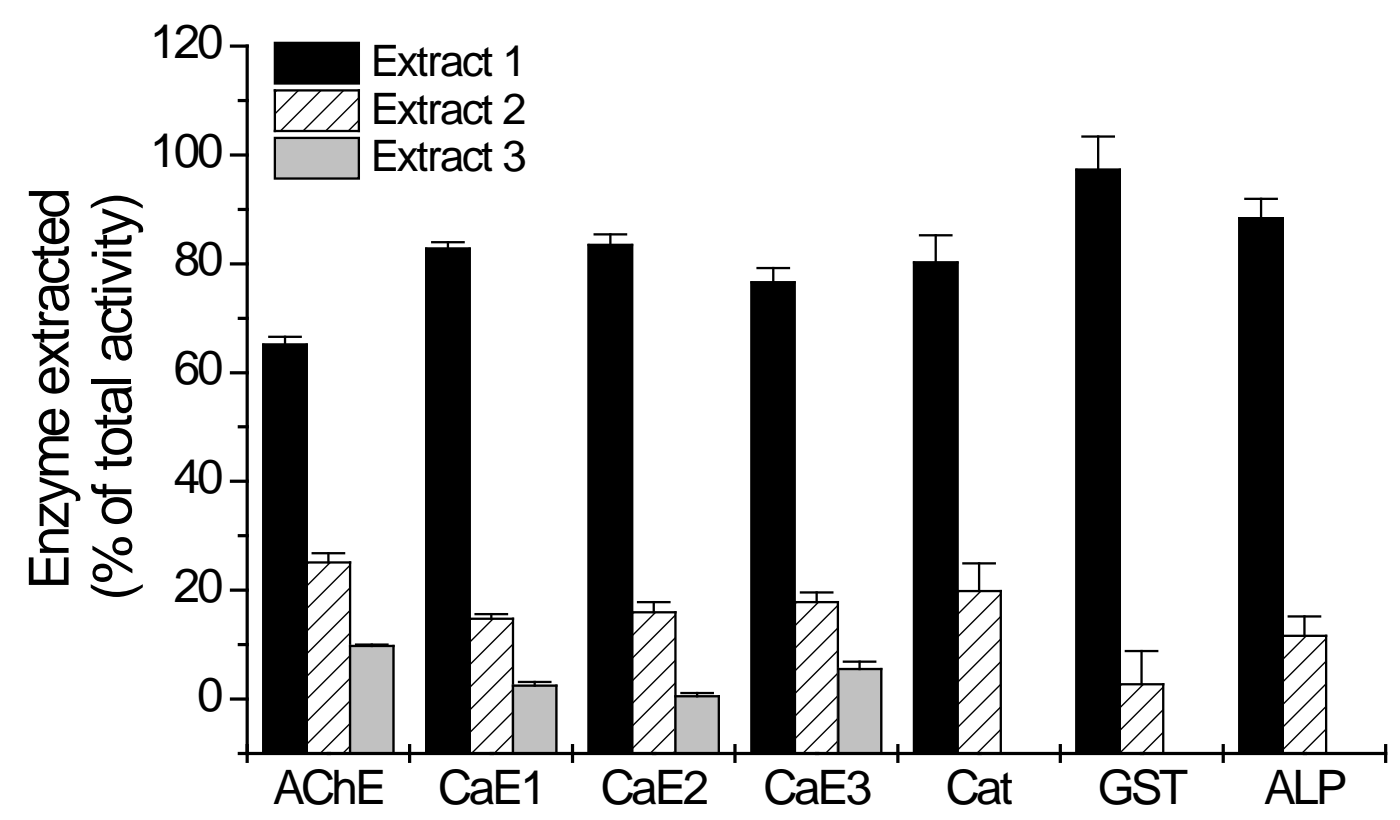

Figure 1 

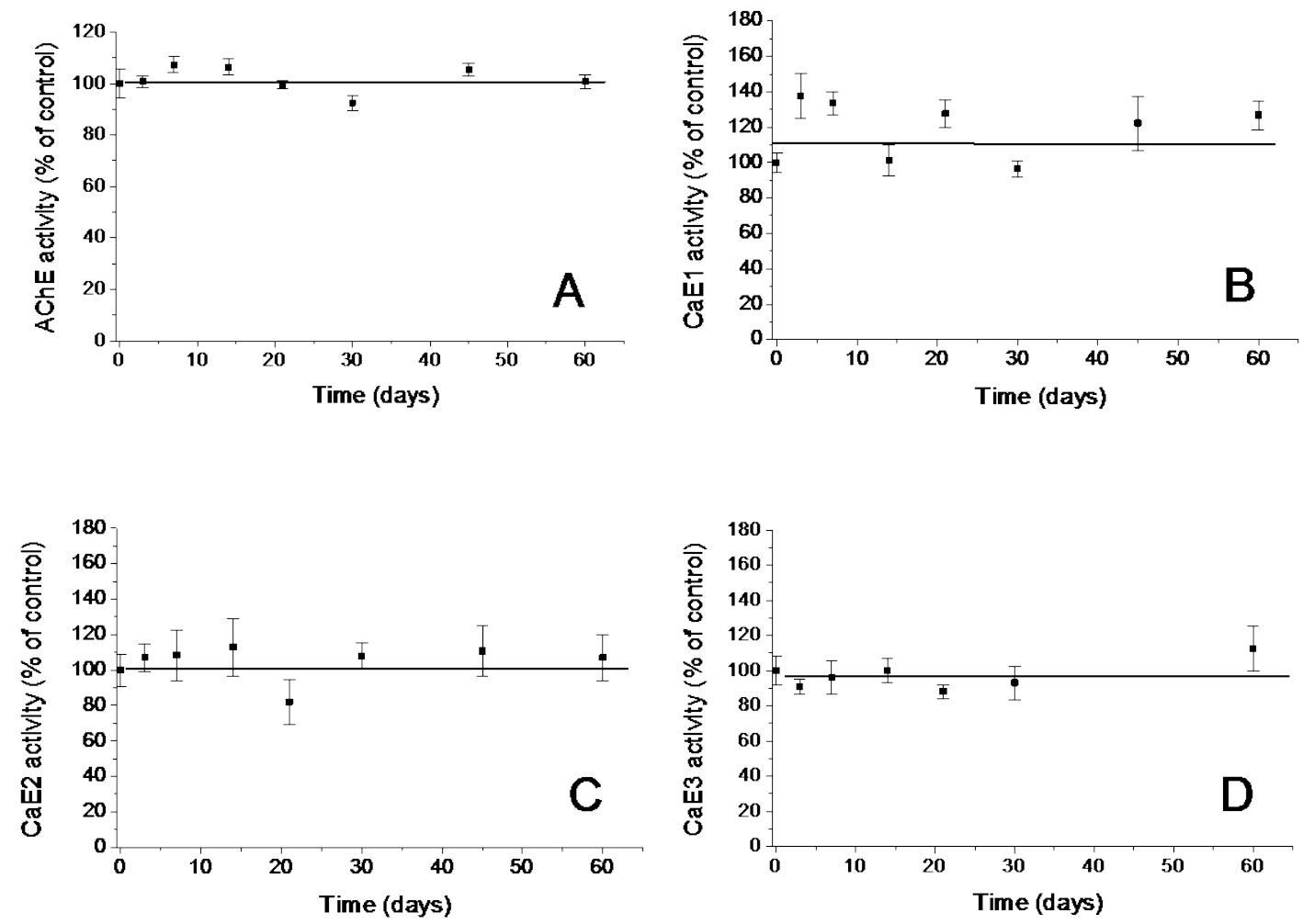

Figure 2

Comment citer ce document 

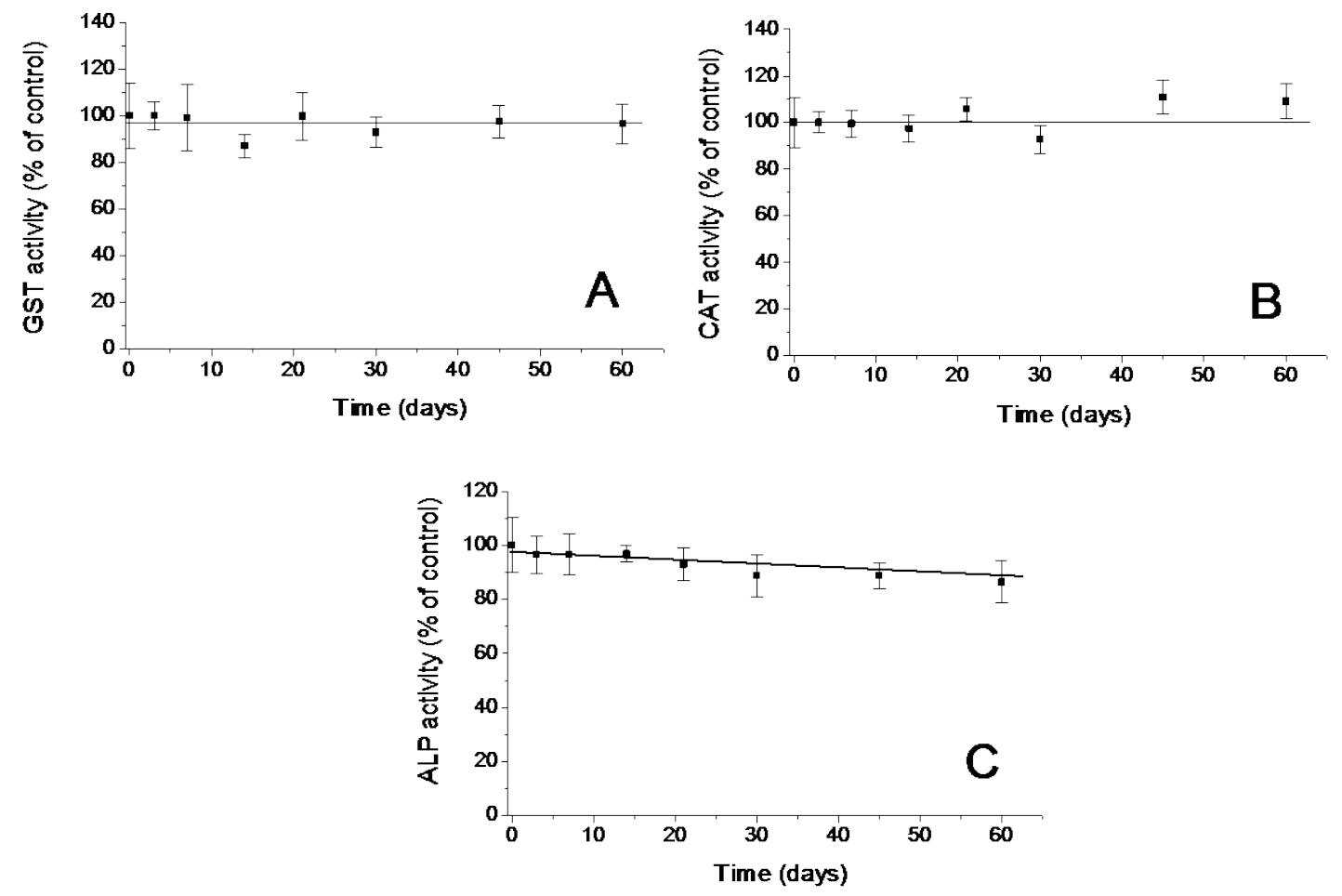

\section{Figure 3}



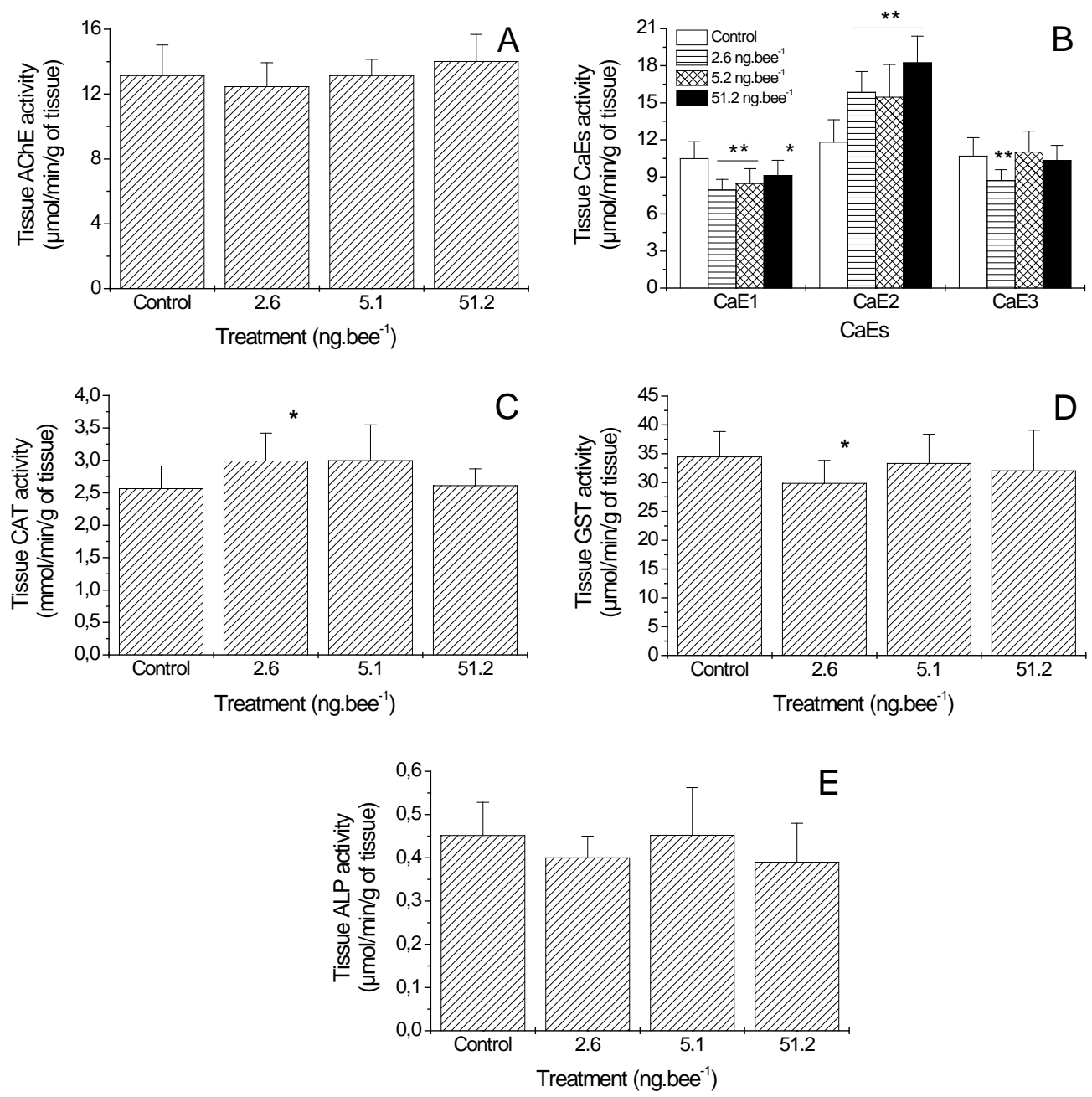

Figure 4 

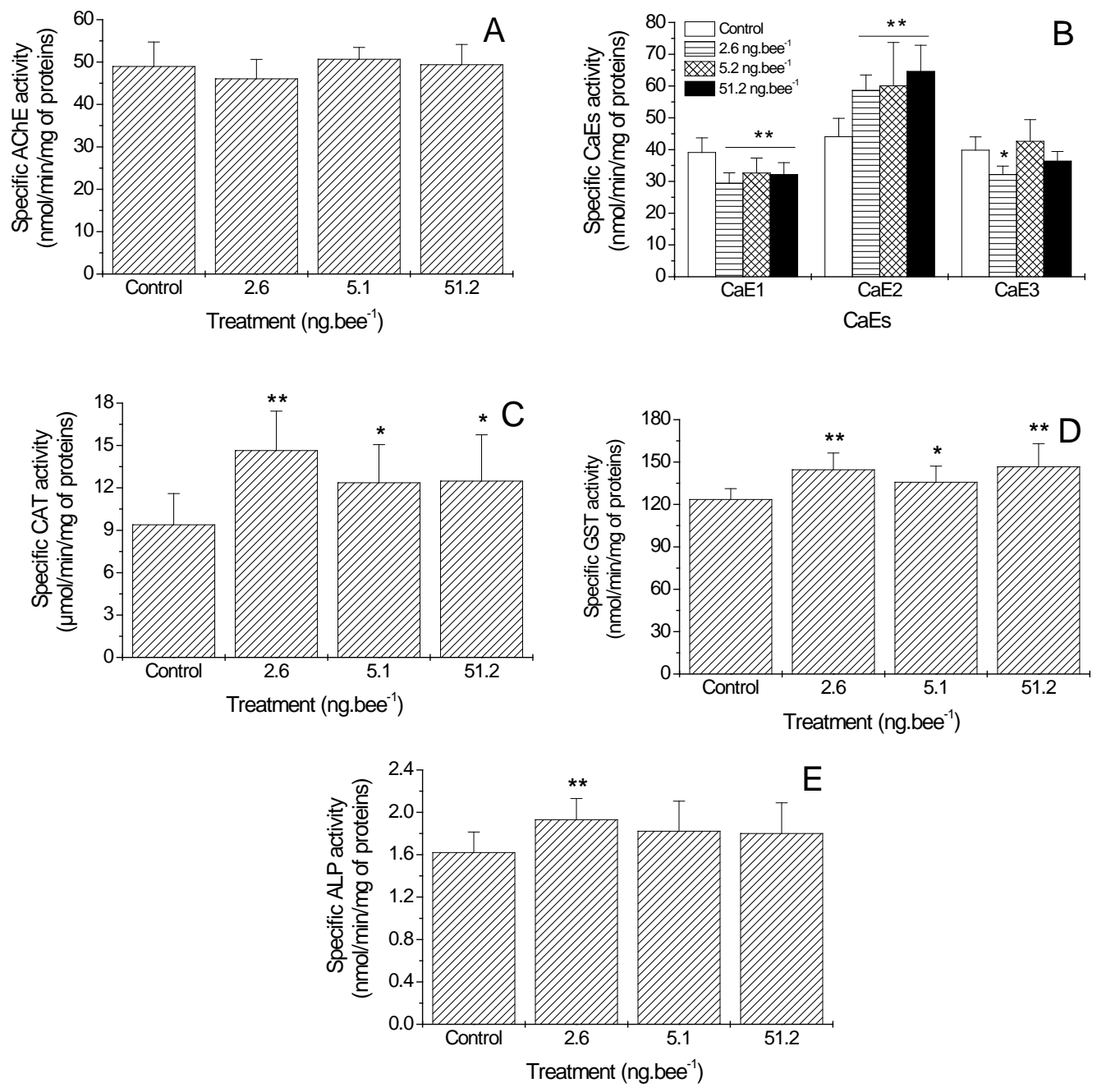

Figure 5 
Table 1. Extraction efficiency of the different enzymes after three sequential extractions (\% of total activity). Data represented the mean values \pm SD and 95\% Confidence Interval in brackets $(n=15)$.

\begin{tabular}{llll}
\hline Enzymes & Extract 1 & Extract 2 & Extract 3 \\
\hline AChE & $65.13 \pm 1.48[64.31 ; 65.95]$ & $25.10 \pm 1.70[24.16 ; 26.04]$ & $9.77 \pm 0,22$ \\
{$[9.65 ; 9.89]$} & $82.77 \pm 1.22[82.1 ; 83.44]$ & $14.74 \pm 0.86[14.26 ; 15.22]$ & $2.48 \pm 0,62$ \\
CaE1 & & $15.98 \pm 1.80[14.99 ; 16.97]$ & $0.56 \pm 0,54$ \\
{$[2.14 ; 2.82]$} & $83.47 \pm 1.94[82.4 ; 84.54]$ & & \\
CaE2 & & $17.86 \pm 1.73[16.9 ; 18.82]$ & $5.56 \pm 1.28$ \\
{$[0.26 ; 0.86]$} & $76.58 \pm 2.59[75.15 ; 78.01]$ & & \\
CaE3 & & $11.61 \pm 3.54[9.65 ; 13.57]$ & Not detected \\
{$[4.85 ; 6.27]$} & $88.39 \pm 3.54[86.43 ; 90.35]$ & $2.72 \pm 0.31[0.66 ; 6.10]$ & Not detected \\
ALP & $97.28 \pm 6.12[93.8 ; 100.66]$ & $19.81 \pm 5.09[17.00 ; 22.62]$ & Not detected \\
GST & $80.19 \pm 5.09[77.38 ; 83.00]$ & & \\
CAT & & &
\end{tabular}

